\title{
To Be Anxious or Not: Student Teachers in the Practicum
}

\author{
Gonca Yangın Ekşi*, Burçak Yılmaz Yakışık \\ Department of English Language Teaching, Gazi University, Turkey
}

Copyright $(2016$ by authors, all rights reserved. Authors agree that this article remains permanently open access under the terms of the Creative Commons Attribution License 4.0 International License

\begin{abstract}
High levels of teaching-related anxiety may cause high levels of stress, failure and disappointment in pre-service teachers. The factors that increase anxiety and those that reduce it for student teachers might also be culture-specific. This study was conducted on 52 pre-service language teachers at a state university in Turkey during their practicum. Rather than investigating the anxiety levels of student teachers, the study aimed to find out the reason why they experienced, or did not experience anxiety with reference to culture specific reasons. This was done by focusing on factors that reduce or provoke practicum anxiety. A questionnaire comprising 25 open-ended questions was developed from the Student Teacher Anxiety Scale (STAS). The items in the scale were converted into questions and the participants were asked to clearly state why they felt anxious or easy. The responses were analysed through content analysis and then quantified to show frequencies. The findings indicated that the student teachers experienced anxiety due to the stress of being evaluated, as well as problem behaviour in the classroom. The results also revealed that helpful and supporting staff at the host school reduces teaching anxiety. The student teachers also felt at ease with a supervisor that they had a partnership with from the micro-teachings in their methodology courses through to supervision in their practicum. The findings are discussed and suggestions regarding improvement in practice teaching are suggested.
\end{abstract}

Keywords Anxiety Increasers, Anxiety Reducers, Evaluation Stress, Practicum, Student Teacher Anxiety

\section{Introduction}

An indispensable component of any teacher education program is the Teaching Practice, or the Practicum. This where student teachers experience actual teaching and culminate experience (Koerner, Rust \& Baumgartner, [1]; Schoeman \& Mabunda, [2]), which allows them to link theoretical knowledge and practice, or the art of teaching (Korthagen \& Kessels, [3]; Stoynoff, [4]). Student teachers view the practicum as the most beneficial and valuable component of their training (Campbell-Evans \& Maloney,
[5]).

Though often cited as a valuable stage of teacher training, the practicum can be a source of stress, worry and concern for student teachers (Behets, [6]; Danyluk, [7]; D'Rozario \& Wong, [8]; McBride, [9]; Murray-Harvey, Silins \& Saebel, [10]; Murray-Harvey, Slee, Lawson, Silins, Banfield \& Russell, [11]; Wendt \& Bain, [12]). It is often found that high levels of anxiety interfere with teaching and may cause problems with certain aspects of the practicum, such as class control (Capel, [13]; Morton, Vesco, Williams \& Awender, [14]; Kazu, [15]). In Chaplain's study [16], student teachers reported behaviour management, workload and lack of support as major causes of stress in their practicum experience. Demands on time management, funding, technology, resources, student behaviour management, administrative and collegiate support, managing a crowded curriculum and examinations are other cited sources of anxiety (Facchinetti, [17]). A lack of role clarification, the evaluation procedure, and not knowing the expectations of the mentor teacher or supervisor may lead to anxiety and stress in the practicum (MacDonald, [18]; Murray-Harvey et al., [11]). In their study of Turkish English Foreign Language (EFL) teacher candidates, Aydın and Bahçe [19] report classroom management as the most cited source of anxiety (43\%); other factors that cause anxiety are the teaching process, relationship with the students, and problems caused by the student teachers' status.

In the literature, evaluation anxiety caused by being observed and assessed by the supervisor is often cited as a major source in the practicum (Capel, [13]). Anxiety may also be induced by the reaction of the supervisor to an unsuccessful lesson (Heeralal, [20]). Anxiety related to controlling the classroom, managing and maintaining discipline, and dealing with disruptive behaviour may lead to high levels of anxiety (Preece, [21]); which may cause discipline problems and thus a destructive cycle. Kyriacou and Stephens [22] list not being regarded as a real teacher, difficulty in behaviour management and the heavy workload as sources of anxiety for student teachers.

Also cited as factors that, increase anxiety are inconsistencies and mismatches between the expectations of supervisors and mentor teachers about student teachers' approach to the Teaching Practice, or the poor quality and 
lack of conformity in feedback from both parties (MacDonald, [23]; Paker, [24]). The relationship with the host school staff, especially those with the mentor teachers, may be another source of anxiety. A good relationship with, and effective guidance and supervision from, the mentor teacher may reduce anxiety in the practicum (MacDonald, [23]; Ngidi \& Sibaya, [25]). Student teachers appear to prefer mentors who are knowledgeable, experienced, honest, respectable, fair, flexible, and understanding. They feel stressed when working with controlling, strict or autocratic mentors (Heeralal, [20]).

Literature on practicum reveals very few studies about the role of culture in teaching anxiety. Morton et al. [14] suggest that variables such as personality, gender, and culture can cause different reactions in the practicum "...male and female student teachers may respond differently to the specific stressors of the teaching experience. Similarly, student teachers in one country may differ in perceived stressors from student teachers in another country" [p. 70)]. In their cross-cultural research, Morton et al. [14] report that Canadian student teachers experienced anxiety related to evaluation, pedagogical, classroom management and staff relations factors and both Canadian and British students were most anxious about evaluation. Murray-Harvey, Silins and Saebel [10] point to the need to understand student stress within a cultural context.

\subsection{Practicum in the English Language Training (ELT) Department in Turkey}

In their final year of study, student teachers (STs hereafter) in English language teacher training programs in Turkey attend primary or secondary schools as a prerequisite for the courses School Experience and Teaching Practice. Before this, in their previous years of study, STs will have taken pedagogy courses such as ELT Methodology, Approaches and methods in language teaching, Material development, Teaching English to young learners, Classroom management, Teaching literature, and Teaching drama, nearly all of which involve micro-teaching demonstrations. The practicum in the final year is supposed to be when STs hopefully mesh the theoretical knowledge gathered so far with actual teaching environments and experiences.

In the School Experience course in their $7^{\text {th }}$ semester, STs spend a day each week in placement schools to familiarise themselves with the teaching profession and the teaching context under the supervision of the mentor teacher. They are required to do structured observation tasks, where after they will receive feedback from their supervisors at the faculty.

In the $8^{\text {th }}$ semester, as a requirement for the Teaching Practice course, the STs perform teaching tasks in classrooms on their weekly visits under the supervision of the mentor teacher. They prepare lesson plans to teach various language aspects, skills or topics. The STs are also observed and evaluated by supervisors from the faculty. The aim is to improve the STs' teaching qualifications and encourage them to act as teachers. In addition to this, they attend feedback sessions in the department with their supervisors and other STs who go to other schools so as to share experiences and opinions.

\subsection{Rationale for the Study, and Research Questions}

This study aims to provide insight into the sources of anxiety. Very few, if any studies, address why STs feel either anxious or at ease about the variables in the literature that are the most cited as sources of anxiety referring to implicit culture-specific reasons. Hence, the present study aimed to investigate why the STs under study either felt anxious, or did not feel anxious at all, based on their accounts of the practicum experience. The extent to which the given group of STs felt anxious is out of the scope of this study.

More specifically, the present study attempted to find answers to these research questions:

1. Among the factors that may cause teaching anxiety, what are the factors that student teachers feel anxious about and why?

2. Among the factors that may cause teaching anxiety, what are the factors that student teachers do not feel anxious about, and why?

3. Are there any factors that are relevant to the Turkish practicum context?

\section{Methodology}

\subsection{Design}

This study was descriptive in nature and aimed to take a closer look at the reasons or factors that make STs feel anxious, or at ease, during their practicum through the use of open-ended questions and follow-up focus group discussions.

\subsection{Participants}

The participants in this study were two randomly drawn groups of $4^{\text {th }}$ year STs from an ELT department at a large state university who took part in the practicum course in the second term. The STs were informed about the aim, and were invited to participate in the study. All of the STs agreed to participate and also granted consent for their answers to the questionnaire and their discussions to be used. Their ages ranged from 21 to 25 years; the mean age for the whole group was $\mathrm{m}=22.8$. The gender distribution was 11 males and 41 females, which is a common ratio in language teaching departments in Turkey.

\subsection{Data Collection Tools}

The research instrument consisted of 40 open-ended questions developed from a standardised anxiety scale called Student Teacher Anxiety Scale (STAS), which was developed by Hart [26] and modified by Morton et al. 
[14].To be precise, the statements in the questionnaire were converted into questions that required elaborate answers from the STs. The scale offers a comprehensive list of potential factors that may cause teaching anxiety in the practicum. Therefore, it is assumed that the open-ended questions converted from the statements in the STAS covers all possible anxiety sources for the participants to comment on and relate to their experiences and feelings. The participants were asked to answer in detail whether they felt anxiety in relation to the items, and to explain why they did or did not.

In order to triangulate the data and to provide more in-depth understanding, the STs were divided into four semi-structured focus groups that were interviewed. The focus group sessions were held at the end of the teaching practicum. A set of key words were prepared by the researcher to lead the conversation and stimulate discussions during the sessions. All of the discussion sessions were audio-recorded with the permission of the interviewees. The participants were not informed about the aim of the study so as to avoid biased statements during the interview.

\subsection{Data Analysis}

Qualitative analysis does not set out to test or prove a pre-formulated hypothesis, but rather takes an inductive approach to analysing data. The data analysis yielded contextual findings which can be transferred to other contexts, rather than broad generalisations. The Constant Comparison Method was used to analyse the qualitative data to draw categories from the relevant data of the specific study instead of using set categories (Glaser \& Strauss, [27]). The responses to the questionnaire and transcripts of the focus group discussions were analysed. Similar codes were collected under the same themes and this qualitative data was then quantified by percentages. Extracts from the STs' responses were also included.

Inter-rater reliability was ensured by calculating $30 \%$ of the whole data through the use of the point by point method (Tawney \& Gast, [28]). The inter-rater reliability was found to be satisfactorily high (.91).

\subsection{Procedure}

STAS has been administered during different stages of practicums; precisely, before, during or after the Teaching Practice (Morton et al., [14]; Paese \& Zinkgraf, [29]; Capel, [13]). In the present study, the questionnaire derived from STAS was administered at the end of the first term when the pre-service teachers had been to the schools for observation but had not yet started their Teaching Practice. The rationale for this timing was that the participants would get to know the teaching staff and the school of placement in the first term and, as a result, fear of the unknown would be eliminated so that the sources of anxiety or ease could be better determined.

At the end of the term, focus group interviews/discussion sessions were held with the participants. Four focus-groups each consisting of 12 or 13 students were given key words for stimulation of discussions and asked to comment on the practicum and sources of anxiety or ease. Their discussions were audio-recorded and transcribed to be analysed.

\section{Findings and Discussion}

An analysis of the qualitative data obtained through the participants' responses indicated six main categories as possible sources of anxiety as experienced by foreign language STs throughout the teaching practicum in Turkey: classroom management, the mentors (the subject teacher and the supervisor), the students and the class profile, teaching procedures, being observed, and miscellaneous (other school staff, the director of the host school, and the luck factor). The following tables present the codes with frequencies both about anxiety increasing and reducing factors in descending order.

The most cited sources of anxiety were related to issues about classroom management. On the other hand, the STs felt at ease because they believed that their training and micro-teachings that they had done earlier qualified them to prepare materials and lesson plans, and manage classrooms effectively. Alternatively, some STs stated that they felt somewhat anxious due to their inexperience. They thought that students might cause problems, however, the presence of the subject teacher appeared to give the STs some relief. There were those who experienced serious anxiety regarding disruptive students as the source of stress and even expressed fear of these students because they did not know how to cope with them. Large classes and time management were other issues that caused anxiety in the STs. One point that needs special attention is the perceived passive role of STs when confronted by the students of the host school. The STs felt happy when the students were cooperative and interested in their lessons, but they were frightened and did not know what to do when learners behaved otherwise. The STs believed that they could not cope with disruptive students. Very high levels of stress caused by disruptive-looking students might be a culture-specific factor in the Turkish context. It was the most frequently cited stressor by the Turkish STs among the anxiety provoking variables (f-32). It appears that while the STs feel quite capable at preparing lesson plans or language teaching materials, they feel threatened by interactions with the students. The "fear of disruptive students" as the most anxiety provoking stressor could be specific to the Turkish context in the relevant literature. 
Table 1. Anxiety increasers and diminishers related to classroom management

\begin{tabular}{|c|c|}
\hline Classroom Management & $\mathrm{f}$ \\
\hline Not anxious & 58 \\
\hline I know how to plan lessons. & 42 \\
\hline I can get all the paper work done in time. & 18 \\
\hline I am accustomed to doing presentations (micro-teaching). & 18 \\
\hline My training is good. & 17 \\
\hline I can handle misbehaviour. & 16 \\
\hline I have enough practice in preparing, adapting and using suitable materials at the right level. & 11 \\
\hline I can conduct enjoyable lessons with interesting topics. & 10 \\
\hline I will try my best to keep eye contact with, and involve all students. & 5 \\
\hline I can create a code of conduct together with students. & 4 \\
\hline Somewhat anxious & 15 \\
\hline I am inexperienced in dealing with misbehaviour. & 12 \\
\hline My lesson content might be boring. & 9 \\
\hline I need more experience studying with real students and keeping them involved. & 4 \\
\hline Ihe subject teacher will be in the class to help me with problem students. & 3 \\
\hline I still feel like a student, not a teacher. & 1 \\
\hline Anxious & 31 \\
\hline My biggest anxiety is disruptive students. I am scared/frightened. & 13 \\
\hline Giving each learner what he/she needs without neglecting others is a problem because of crowded classes. & 12 \\
\hline I am not competent enough in classroom management. I need much more experience. & 5 \\
\hline
\end{tabular}

Table 2. Anxiety increasers and diminishers related to mentors (supervisors and the subject teachers)

\begin{tabular}{|c|c|}
\hline \multicolumn{2}{|l|}{ MENTORS } \\
\hline Supervisor & \\
\hline Not Anxious & $f$ \\
\hline I know my supervisor, we are familiar with her style/expectations & 32 \\
\hline $\begin{array}{c}\text { In the case of one or more unsuccessful lessons, I know my supervisor will be tolerant at first and expect us to become } \\
\text { better in other lessons. }\end{array}$ & 28 \\
\hline We are used to being observed by our supervisor, and are used to her type of feedback. & 13 \\
\hline My supervisor clearly explains what she expects. & 12 \\
\hline My supervisor is tolerant/ understanding and fair. & 11 \\
\hline My supervisor is the best person to help me notice my deficiencies. & 6 \\
\hline \multicolumn{2}{|l|}{ Somewhat Anxious } \\
\hline My supervisor will expect what she has taught us, and expects to see the result of the four year training. & 17 \\
\hline \multicolumn{2}{|l|}{ Anxious } \\
\hline My supervisor is too experienced and knows all, sees all. & 16 \\
\hline I do not know when my supervisor will come. I would be more relaxed if I was notified of the observations beforehand. & 11 \\
\hline I would like to know what criteria my supervisor will use to evaluate us. & 2 \\
\hline My supervisor's impression of me is poor. I did not attend regularly. & 2 \\
\hline My supervisor was not my methodology instructor. I am not familiar with her. & 1 \\
\hline \multicolumn{2}{|l|}{ Subject Teacher } \\
\hline \multicolumn{2}{|l|}{ Not Anxious } \\
\hline The subject teacher is kind/helpful/understanding/encouraging & 47 \\
\hline The subject teacher likes the materials we have prepared. & 2 \\
\hline \multicolumn{2}{|l|}{ Somewhat anxious } \\
\hline $\begin{array}{l}\text { I would really like to create a good impression on the subject teacher. Her ideas are important. I do not want to } \\
\text { disappoint her. }\end{array}$ & 11 \\
\hline I am not sure whether what I will do would fit in with what the subject teacher would do. & 10 \\
\hline She is too experienced. & 10 \\
\hline In the case of an unsuccessful lesson, the subject teacher may not interfere but may worry that I will do that gain. & 5 \\
\hline
\end{tabular}


A great many STs expressed comfort in their familiarity with the supervisor and the fact that they had been observed and had been given feedback by her during the micro-teachings previously. Knowing her expectations and believing that she would help them improve helped STs to relax in their Teaching Practice. The STs also expressed relief as they knew they would have more chances in their next observations. They also stated that the supervisor would like to see the results of the four year training, which made them feel somewhat anxious. The supervisor's experience, however, caused stress for the STs who believed that she would see all when they made a blunder in class. Not knowing when she would pay a visit or how she would evaluate them are other factors that caused anxiety in the STs. Two STs express their concerns as they believed that they had made a poor impression on the supervisor because they had not attended classes regularly. One ST, who had not taken the supervisor's methodology courses before, expressed worry. It appears that familiarity with and taking methodology courses from the supervisor are the greatest anxiety diminishers for STs in the practicum.

As to the subject teacher, the STs expressed that they did not feel any anxiety at all because the subject teacher was kind and understanding and gave encouragement and praise. However, concerns related to her impression about them and her expectations of their teaching ability made STs feel somewhat anxious. None of the STs expressed factors that made them feel very anxious. It can be concluded that these STs felt quite relaxed when studying with a supervisor that they had known before, as well as working with a helpful and encouraging subject teacher. The STs felt at ease when the subject teacher allowed them to put into practice their own teaching methodologies, techniques and material. This finding is in line with that of (Kiggundu \& Nayimula, [30]), suggesting that exclusion from school activities and feeling insignificant discouraged the STs.

Table 3. Anxiety increasers and diminishers related to the students and the class Profile

\begin{tabular}{|c|c|}
\hline Students and the Class Profile & f \\
\hline Not anxious & \\
\hline Students seem fine, cooperative and respectful. & 36 \\
\hline Somewhat anxious & \\
\hline They get bored easily. & 8 \\
\hline I do not know them well. & 3 \\
\hline Anxious & \\
\hline Some students really misbehave. & 17 \\
\hline
\end{tabular}

Many STs (n.36) regarded the students at the host school as "cooperative and respectful" and thus they felt relief in the classroom. However, when the STs thought that the students got bored easily and/or they do not know the students well, they felt somewhat anxious. The STs felt stressed when they discussed the students that misbehaved, though only "some" of the students did so. This finding corresponds with their responses regarding classroom management issues. The greatest source of anxiety for the STs stemmed from their perceived inability and inexperience to cope with disruptive students. More than just a plain anxiety-provoking variable, disruptive or misbehaving students were regarded as fearsome by the STs in the Turkish context. This might be due to the authoritarian role of the teacher in the classroom in the Turkish culture. As the STs did not have such a power on the students, they might feel disadvantaged.

Table 4. Anxiety increasers and diminishers related to teaching procedures

\begin{tabular}{|c|c|}
\hline Teaching Procedures & $\mathrm{f}$ \\
\hline Not anxious & \\
\hline My training at university is adequate. I am qualified enough. & 35 \\
\hline I can effectively use/ adapt and produce materials. & 24 \\
\hline I can handle selecting suitable lesson content. & 13 \\
\hline The course book is of great help. & 7 \\
\hline $\begin{array}{c}\text { I can use multimedia to create interesting and suitable lesson } \\
\text { content. }\end{array}$ & 6 \\
\hline I can handle technology in class. & 4 \\
\hline Anxious & 21 \\
\hline $\begin{array}{c}\text { The final year will be too loaded and difficult to prepare for } \\
\text { the lessons because of extra studies (KPSS). }\end{array}$ & 7 \\
\hline I cannot decide whether the level of activities is suitable. & \\
\hline
\end{tabular}

The statements regarding teaching procedures were mostly positive, indicating self-confidence in their ability to produce materials, prepare lesson plans, select lesson content and use technology thanks to their in-service training. The main source of anxiety in this section resulted from extraneous factors such as time management. The final year is too loaded for STs as they have to attend the university courses along with private courses, and need to attend these to pass the KPSS (a selection exam for professional posts in public organisations in Turkey). The STs often study for a high-stakes exam to be able to attend state schools in Turkey. The exam is used to select teachers, and the additional burden to study for it makes it difficult for STs to prepare for the practicum in their final year. An exam-oriented culture appears to cause STs to experience higher stress and this finding is in line with that of Murray-Harvey et. al [10] about Singaporean STs. In comparison, a smaller number of STs expressed that they felt stress because of not being able to decide on the appropriate level of activities.

Table 5. Anxiety increasers and diminishers related to being observed

\begin{tabular}{|c|c|}
\hline Being Observed & $\mathrm{f}$ \\
\hline Not anxious & \\
\hline Having planned and being ready for each lesson might help. & 18 \\
\hline Our training has prepared us for that. & 12 \\
\hline Anxious & \\
\hline Being observed is stressful and getting a grade is stressful. & 26 \\
\hline Nervousness can cause me to make mistakes. & 17 \\
\hline I do not know when the supervisor will come to observe me. & 15 \\
\hline The real thing is different. & 12 \\
\hline I get stressed easily. & 6 \\
\hline
\end{tabular}


As to being observed by the supervisor, the STs expressed a great amount of concern related to being evaluated. The fact that the observation is eventually an evaluation with a grade appeared to make them nervous. Most of the STs were troubled that nervousness could cause them to perform poorly during their practice. This finding is in line with previous research in different countries (D'Rozario \& Wong, [8]; Hart, [26]; Morton et al., [14]; Paker, [24]). This finding also supports the finding that "evaluation anxiety appears to be paramount regardless of country" (Morton et al., [14. p. 72]).

The STs also felt unprepared due to not receiving notice as to when observations would take place, which they found stressful. Not knowing when the supervisor would visit was a source of anxiety. The STs also expressed concern that the actual teaching environment was different from the micro-teachings. A smaller number of STs (n.6) stated that their anxiety resulted from personality, saying that they easily got stressed. In contrast with these factors that cause anxiety in STs, many stated that their pre-service training was helpful and that being prepared at all times would help overcome the anxiety caused by un-notified visits.

Table 6. Anxiety increasers and diminishers related to miscellaneous factors (school staff, the director, and luck)

\begin{tabular}{|c|c|}
\hline Miscellaneous & $\mathrm{f}$ \\
\hline \multicolumn{2}{|l|}{ School Staff } \\
\hline \multicolumn{2}{|l|}{ Not anxious } \\
\hline $\begin{array}{l}\text { Members of the school staff are very kind and helpful/ } \\
\text { understanding. }\end{array}$ & 56 \\
\hline The teachers are cooperative. & 15 \\
\hline It is good if you can find someone to answer your questions. & 2 \\
\hline \multicolumn{2}{|l|}{ Anxious } \\
\hline $\begin{array}{c}\text { Some do not care; they behave as if they do not want any of us } \\
\text { around. }\end{array}$ & 5 \\
\hline \multicolumn{2}{|l|}{ Director/Principal } \\
\hline \multicolumn{2}{|l|}{ Not anxious } \\
\hline $\begin{array}{l}\text { I believe that the materials I use, or what I do will make the } \\
\text { principal happy. }\end{array}$ & 9 \\
\hline The school principal is helpful and kind. & 7 \\
\hline \multicolumn{2}{|l|}{ Somewhat anxious } \\
\hline $\begin{array}{l}\text { The school director is far from the teaching circle. Not much } \\
\text { contact/ do not know what he expects. }\end{array}$ & 5 \\
\hline $\begin{array}{l}\text { I may not be able to catch up with his expectations because of } \\
\text { my inexperience. }\end{array}$ & 4 \\
\hline It is important that the principal be happy. & 3 \\
\hline The school director is the authority in the school. & 2 \\
\hline \multicolumn{2}{|l|}{ Luck } \\
\hline \multicolumn{2}{|l|}{ Anxious } \\
\hline Unexpected things might happen. & 15 \\
\hline What I will teach on the observation day is a matter of luck. & 17 \\
\hline
\end{tabular}

As to other factors that cause anxiety or ease, the STs regarded the cooperativeness, kindness and understanding of teachers and the school staff as effective anxiety diminishers. They felt more comfortable when they could find someone to answer their questions, but they felt stressed if the school staff seemed as if they did not care or were unfriendly (only in a few cases, n.5). The STs also thought it was important to meet the expectations of the director of the school as he is the authority in the school. Those who felt somewhat anxious stated that their own inexperience or unfamiliarity with the director's expectations were sources of anxiety. Those who expressed no anxiety at all pointed to their confidence in their teaching skills and the personality of the director as to why they felt at ease. Interpersonal relationship items, particularly those with the disruptive students and the principal might be a major factor in creating stress whereas items related to lesson preparation caused very little stress in the Turkish context. This finding was totally the opposite of Murray-Harvey, Silins \& Saebel's [10] study in which interpersonal relations were the least stressful.

One final factor that caused stress was the luck factor. Quite a number of STs stated that they felt stressed because it was a matter of luck that unforeseen things might happen. They also felt that the topic or language skill they would be teaching during the supervisor's visit was a matter of luck.

Table 7. Focus group discussions

\begin{tabular}{|c|c|}
\hline Anxiety increasers & Anxiety diminishers \\
\hline Classroom management & The supervisor \\
Disruptive students and misbehaviour & Helpful school staff \\
Lack of motivation by students & Training at university \\
Being evaluated & \\
Putting theory into practice & \\
\hline
\end{tabular}

The focus group discussions with the STs yielded the following factors as main sources of anxiety: classroom management problems, mainly resulting from inexperience; disruptive students, and not knowing how to cope with them; lack of motivation by some students, and failing to integrate them into the lessons; the fear of being evaluated and getting a grade at the end; and the challenge of putting theory into practice.

As to factors that put the STs at ease, the supervisor was often cited as a source of relief. The host school staff and subject teacher being helpful also helped the STs to relax during the practicum. Lastly, their in-service training, which required them to do lots of micro-teaching demonstrations, prepare plenty of lessons plans, create and adapt materials also helped them to feel at ease in the practicum. They also believed that they had covered and mastered the pedagogy efficiently as well.

\section{Conclusions}

The practicum is a vital component of teacher training programs. This study examined student teachers' perceptions of the sources of anxiety related to the Teaching Practice. The study also focused on factors that help STs overcome practicum anxiety.

It is expected observe similarities between groups who share common features in their cultures (Morton et. al [14]) 
and significant differences in stress items and levels might indicate a need to refer to the cultural context for deeper understanding. These differences might be attributed to differences in culture and education system, the role of the teacher, level of formality between parties involved. Hyland and Lo [31] mentioned previous research in which culture may be influential in mentors' level of directness and the STs reaction to this and that people from different cultures interact differently in spoken discourse. In the Turkish education context, the teacher has a relatively more authoritarian role and is expected to be in control in the classroom. The present study appears to indicate that STs experience stress as they think they do not have authority over students in the classroom. Those who believe they look authoritarian feel lucky as they believe it would help them to establish and maintain classroom management. Interpersonal relations with the school principal and the students, if they seem distant and uncooperating, might cause stress whereas a helpful subject teacher or the supervisor diminish the stress level. The Turkish context displays interpersonal factors as more important in determining stress levels than those related with the self. A brief list of factors that appear to be specific to the Turkish context were disruptive students as the STs did not know how to cope with them; a high-stake exam that they had to take to be recruited and the additional burden on their already busy schedule. Interestingly though, the school principal as an important figure was cited by most of the STs. The STs also mentioned that it was a matter of luck whether they could perform well or not because of the topic of the day and the un-notified visits. As for factors that reduce anxiety, it was noteworthy to observe that the STs regarded "having an authoritarian look" as an advantage. Cooperation and understanding by the teaching staff was regarded as relieving, which indicated a need to be surrounded by a supporting community.

Given the participants' statements regarding factors that increase and diminish anxiety, it appears that STs are most anxious about being evaluated; dealing with disruptive students, un-notified visits, and classroom management problems. The STs expressed anxiety due to being evaluated, and the possibility of making mistakes and failing to meet the expectations of the supervisor. Still, there seems to be a need for tertiary institutions to assign to the STs supervisors who lectured them in previous years. An unbroken and continuous partnership from the micro-teachings in methodology courses through to supervision in the practicum appear to be preferred by the STs. Familiarity with the trainer and his/her expectations, and the way that they give feedback helped the pre-service teachers function with more confidence and ease. However, un-notified observation visits caused stress for the STs as they believed that what they taught on that day was a matter of luck. Briefing, that is, informing STs about what is expected of them during the Teaching Practice might be an effective anxiety diminisher. Effective supervision and guidance from subject teachers at the schools of placement can also play an important role in reducing anxiety among STs. When studying with a helpful and encouraging subject teacher, the STs stated that they felt comfortable and at ease. However, they experienced some anxiety when the expectations of their supervisor and mentor subject teachers did not correspond.

An important finding of the study suggests that STs lack confidence in dealing with problem behaviour in the classroom, with some describing it as a fearsome phenomenon. They also believe that they are too inexperienced and totally ineffective in the case of disruptive students. Methodology courses should also involve guidance on how to prevent problem behaviour. Other aspects of classroom management, such as planning lessons and materials, seem not to create anxiety for the STs as they believe that their in-service training has equipped them with the necessary skills. It appears that language teacher training programmes should often require the STs to put their theoretical knowledge into practice as much as possible in micro-teachings or similar tasks. The study also suggests that a practicum experience that reduces teaching anxiety involves a friendly and helpful host school staff and a supervisor that they are familiar with from previous courses at university.

\section{REFERENCES}

[1] Koerner, M., Rust, F., \& Baumgartner, F. Exploring roles in student teaching placements. Teacher Education Quarterly, 2002, Spring, 35-58.

[2] Schoeman, S., \& Mabunda, P. L. Teaching practice and the personal and socio-professional development of prospective teachers. South African Journal of Education, 2012, 32:240-254.

[3] Korthagen, F. A. J., \& Kessels, J. P. A. Linking theory and practice: Changing the pedagogy of teacher education. American Educational Research Association, 1999, 28(4): 417.

[4] Stoynoff, S. The TESOL practicum: An integrated model in the U.S. TESOL Quarterly, 1999, 33 (1): 145-151.

[5] Campbell-Evans, G., \& Maloney, C. Trying to make a difference: Re-thinking the practicum. Paper presented at the annual conference of the Australian Association for Research in Education, Hobart, Australia, 1995.

[6] Behets, D. Concerns of pre-service physical education teachers. Journal of Teaching in Physical Education, 1990, 10:66-75.

[7] Danyluk, P. The Role of the Pre-practicum in Lessening Student Teacher Stress: Student Teachers' Perceptions of Stress During Practicum, Action in Teacher Education, 2013, 35:5-6, 323-334.

[8] D'Rozario, V., \& Wong, A. F. A study of practicum-related stresses in a sample of first year student teachers in Singapore. Paper presented at The annual conference of the Singapore Educational Research Association and Australian Association for Research in Education, Singapore, 1996. 
[9] McBride, R. E. Perceived teaching and program concerns among pre-service teachers, university supervisors, and cooperating teachers. Journal of Teaching in Physical Education, 1984, 3:36-43.

[10] Murray-Harvey, R., Silins, H., \& Saebel, J. A cross-cultural comparison of student concerns in the teaching practicum. International Education Journal, 1999, 11(1): 32-44.

[11] Murray-Harvey, R., Slee, P. T., Lawson, M. J., Silins, H. C., Banfield, G., \& Russell, A. Under Stress: The concerns and coping strategies of teacher education students, European Journal of Teacher Education, 2000, 23: 19-42.

[12] Wendt, J. C., \& Bain, L. L. Concerns of pre-service and in-service physical educators. Journal of Teaching in Physical Education, 1989, 8:177-180.

[13] Capel, S. A. Changes in students' anxieties and concerns after their first and second teaching practice. Educational Research, 1997, 39:211-228.

[14] Morton, L. L., Vesco, R., Williams, N. H., \& Awender, M. A. Student teacher anxieties related to class management, pedagogy, evaluation, and staff relations. British Journal of Educational Psychology, 1997, 67:69-89.

[15] Kazu, K. Anxiety in college Japanese language classroom. Modern Language Journal, 2001, 85:549-567.

[16] Chaplain, R. P. Stress and Psychological Distress among Trainee Secondary Teachers in England. Educational Psychology, 2008, 28(2): 195-209.

[17] Facchinetti, A. Education revolution? Education Today, 2010, 10.

[18] MacDonald, C. J. The multiplicity of factors creating stress during the teaching practicum: the student teachers' perspective. Education, 1992, 113 (1): 48-58.

[19] Aydın, B., \& Bahçe, A. Cases from student teachers. Paper presented at the International ELT Conference- 2001 on 'Searching for Quality in ELT, Eastern Mediterranean University, Gazimagusa, May 2-4, 2001.
[20] Heeralal, P. J. H. Student teachers' perspectives of good mentor teachers. Anthropologist, 2014, 17(1): 243-249.

[21] Preece, P. F. W. Student teacher anxiety and class-control problems on teaching practice: A cross-lagged panel analysis. British Educational Research Journal, 1979, 5(1): 13-19.

[22] Kyriacou, C., \& Stephens, P. Student teachers' concerns during teaching practice. Evaluation and Research in Education, 1999, 13(1): 18-31.

[23] MacDonald, C. Coping with stress during the teaching practicum: the student teacher's perspective, The Alberta Journal of Educational Research, 1993, 39: 407-418.

[24] Paker, T. Student teacher anxiety related to the teaching practicum. Eurasian Journal of Educational Research, 2011, 42: $207-224$.

[25] Ngidi, D. P., \& Sibaya, P. T. Student teacher anxieties related to practice teaching. South African Journal of Education, 2003, 23(1): 18-22.

[26] Hart, N. I. Student teachers' anxieties: four measured factors and their relationships to pupil disruption in class, Educational Research, 1987, 29 (1): 12-18.

[27] Glaser, B. G., \& Strauss, A. The Discovery of Grounded Theory: Strategies for Qualitative Research. New York: Aldine De Gruyter, 1967.

[28] Tawney, J. W, \& Gast, D. L. Single subject research in special education. Columbus, $\mathrm{OH}$ : Charles E. Merrill Co, 1984.

[29] Paese, P. C. \& Zinkgraf, S. The effect of student teaching on teacher efficacy and teachers stress. Journal of Teaching in Physical Education, 1991, 10:307-315.

[30] Kiggunda, E., \& Nayimuli, S. Teaching practice: A make or break phase for student teachers. South African Journal of Education, 2009, 29: 345-358.

[31] Hyland, F. \& Lo, M. M. Examining interaction in the teaching practicum: issues of language, power and control. Mentoring \& Tutoring: Partnership in Learning, 2006, 14 (2): 163-186. 